\title{
Analysis of Student Utilization and Activities in a Campus Innovation Center
}

\section{Dr. William A. Kline, Rose-Hulman Institute of Technology}

Bill Kline is Professor of Engineering Management and Associate Dean of Innovation at Rose-Hulman. His teaching and professional interests include systems engineering, quality, manufacturing systems, innovation, and entrepreneurship. As Associate Dean, he directs the Branam Innovation Center which houses campus competition teams, maker club, and projects.

He is currently an associate with IOI Partners, a consulting venture focused on innovation tools and systems. Prior to joining Rose-Hulman, he was a company co-founder and Chief Operating Officer of Montronix, a company in the global machine monitoring industry.

Bill is a Phi Beta Kappa graduate of Illinois College and a Bronze Tablet graduate of University of Illinois at Urbana Champaign where he received a Ph.D. degree in Mechanical Engineering.

\section{Dr. Timothy Chow, Rose-Hulman Institute of Technology}

Dr. Tony Ribera, Rose-Hulman Institute of Technology

Tony Ribera serves as the Director of Assessment in the Office of Institutional Research, Planning and Assessment at Rose-Hulman Institute of Technology. He most recently worked at the Indiana University School of Medicine where he served as the Director of Program Evaluation in the Office of Medical Student Education. Tony has a PhD from Indiana University in Higher Education and Student Affairs. 


\section{Analysis of Student Utilization and Activities in a Campus Innovation Center}

The Branam Innovation Center (BIC) has served our campus for six years providing support for competition teams, capstone and class projects, a maker space, and other campus activities. The 16,000 sq. ft. center provides project space, supervision, and access to fabrication and prototyping resources. It has been a popular and increasingly utilized resource with student entries to the building increasing 1.35 times in the last two years.

Several aspects of maker and innovation centers have been reported on including a classification system, operating policies, training programs, and assessment approaches. This paper will report on student utilization of our innovation center through the analysis of activity records. Over the years of operation of the center, multiple measures of student activity and utilization have been collected including lock logs, team rosters, and training completions. This paper will analyze these sources of data and report on several aspects of growth and utilization of the center including: (a) overall level of student activity over the last three years; (b) student activity broken down by time of year, quarter, and day; (c) student gender and class standing; and (d) student participation in training classes. The paper will also report on assessment approaches that have been used and general student feedback on the center and activities. It is believed that these results are useful in a variety of situations including prioritizing center activities, marketing the program to students, allocating space, scheduling staff, and determining overall resource needs.

\section{Background on University Innovation and Maker Centers}

Innovation centers and maker spaces have appeared on university campuses within the last 20 years to nurture creativity, design, self-learning, and hands-on fabrication skills in undergraduate students. While maker spaces often support a student community of makers and their cocurricular projects, our innovation center houses competition teams, capstone projects, class projects, and a maker space.

Several maker programs have been described in the literature. The 'BucknellMakers' program makes tools widely available, offers training and skill development, and encourages curricular and co-curricular experiences ${ }^{1}$. The Georgia Tech 'Invention Studio' is managed by students and supports over 1000 students per month engaged in both class and personal projects. The cultural benefits of the studio for both students and the university are noted ${ }^{2}$.

Results from the development and operation of maker spaces and centers have been reported. The acronym 'SPACE' has been suggested as providing important direction - Student involvement, Pick a high traffic space, Adaptability, Culture, and Equipment should be unintimidating ${ }^{3}$. The Invention Studio has reported on their approaches to staffing, equipment, safety, IP, funding, and outreach ${ }^{2}$. More detailed operational practices are summarized including a smart badging system ${ }^{4}$ and approaches for equipment utilization ${ }^{5}$.

As various types of maker and innovation centers have emerged, a classification system has been proposed which includes scope, accessibility, users, footprint, and staffing as classification 
attributes $^{6}$. Reviews of maker spaces have reported including: (a) ratios of users to space and supervision to users ${ }^{7}$, and (b) location, use policies, and equipment availability ${ }^{8,9}$.

Assessment studies of maker and innovation centers, are appearing and while still preliminary, suggest that in addition to improving innovation and hands-on building skills, innovation and maker centers could increase student confidence, increase retention, and create a sense of belonging ${ }^{10,11}$.

\section{Vision and Operation of the Center}

The Branam Innovation Center (BIC) opened in the fall of 2011. Constructed in a simple openconcept style with reused/recycled furnishings, the 16,000 sq. ft. building houses competition teams, capstone projects, class projects, and a maker space. The center provides working space, tools, materials, training, and supervision for students working in the building. Special fabrication areas include a machine shop, welding shop, paint booth, wood/dust shop, and rapid prototyping/maker equipment. The center is staffed for 90 hours of operation per week by staff and student workers.

Students gain access to working in the center through membership in one of the supported groups and by completing a series of online and face-to-face training sessions. Students may join one of the competition teams at any point during the year and capstone students work in the center when enrolled in their courses. The MakerLab club is the easy entry point for students who want to work on their own projects in the center.

Entry to the center during supervised hours requires completing two online training modules in environmental, health, and safety and 5S. The center has one main entry door which is locked 24/7. Campus IDs are scanned at the front door to provide entry. Additional face-to-face (F2F) training is required to enter the machine and welding shops.

Environmental, Health, and Safety (EHS) and risk management policies have been developed in cooperation with the relevant campus offices. The policies span a range of operating rules, supervision, training requirements, shop access, and student travel. Of note is that the machine and welding shops are open only during supervised hours while the main areas of the center with no hazardous equipment are open 24/7 to students with additional training.

The 5S approach has recently been introduced to help set a standard for housekeeping and neatness in project areas. $5 \mathrm{~S}$ is a workplace organization method that focuses on organizing a work space for effectiveness and reducing waste. The name comes from the five Japanese words that help define the phases of the approach. 5S audits of workspaces are conducted multiple times each quarter with scores and rankings tallied and posted.

Competition teams and clubs are assigned dedicated workbays ranging from 300 to 900 square feet. Capstone teams in ME, ECE, and BE are assigned either workbench space or shared floor space depending on the nature of the project. 
With a focus on creating a collaborative and innovative culture, the center provides easy access to tools, materials, and consumables. Students are prohibited from bringing their own tools into the center and materials/supplies for competition teams are provided. A variety of training classes are offered to students to develop safety, skill, and professional competencies.

The center connects and provides value to several other campus offices including admissions, career services, and institutional advancement. The BIC is a regular and popular stop for admissions campus visitors. We communicate regularly with admissions staff and student tour guides so they are able to provide a detailed and exciting introduction to the center. The center is also a connection point for corporate partners and these relationships are cultivated through the career services and institutional advancement offices.

\section{Analysis of Team Memberships}

Table 1 and Figure 1 summarize team and group memberships for the center from inception to the current year. At the current time, the center is reaching about $30 \%$ of the campus student population in some way. These data come from Moodle groups and rosters.

\begin{tabular}{|l|r|r|r|r|r|r|r|}
\hline Membership & 2011-12 & \multicolumn{1}{|c|}{$2012-13$} & $2013-14$ & $2014-15$ & $2015-16$ & $2016-17$ & 2017-18* \\
\hline Competition Teams & 151 & 163 & 224 & 314 & 356 & 365 & 313 \\
\hline Maker Club & & & & 42 & 53 & 75 & 56 \\
\hline Classes/Events & & & & & & 121 & 183 \\
\hline Capstone & & & 16 & 101 & 146 & 133 & 171 \\
\hline Other & & 40 & 40 & & & & \\
\hline & 151 & 203 & 280 & 457 & 555 & 694 & 723 \\
\hline
\end{tabular}

Table 1 - Student Membership in BIC Groups

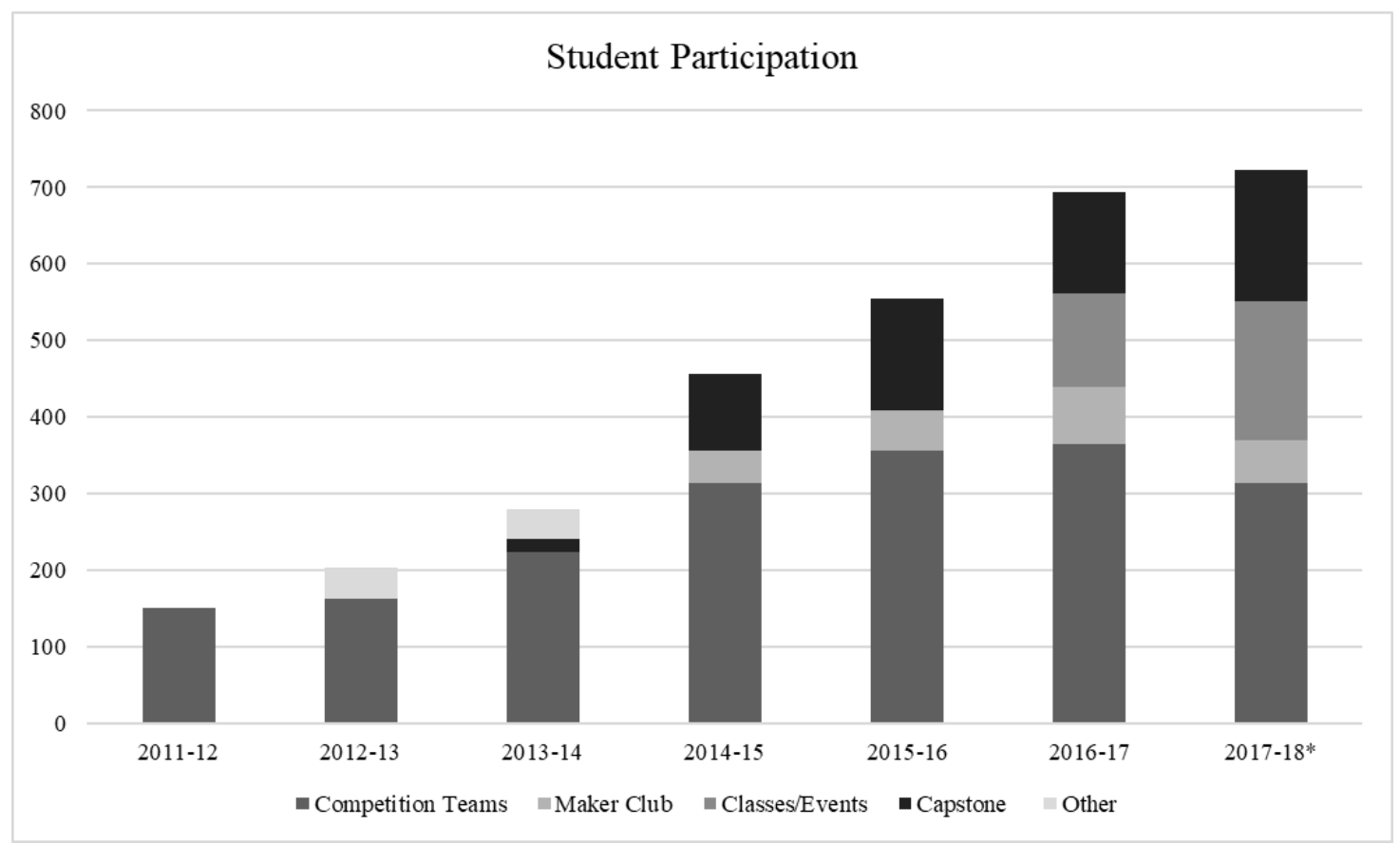

Figure 1 - Student Membership in BIC Groups 
In the first two years, the center housed only competition teams. In the later years, additional competition teams, capstone projects, classes, and events are using the center. Current competition teams include Formula SAE, Human Powered Vehicle, Concrete Canoe, Rose Efficient Vehicle, First Robotics, Chemical Car, Autonomous Vehicle, and Robotics (with four sub-teams).

The table and figure show that competition team memberships have increased due to more teams and increased interest. In the current year, team memberships have declined slightly as two teams are in a period of transition with changing student leadership.

The center began housing capstone project workspaces in 2013 and now supports 171 capstone students in ME, BE, and ECE. Use by classes and events has also increased to over 150 students. Class use varies during the year but has included freshman design, design for manufacturing, and sustainable technologies classes. Use by shorter duration campus events has included diversity related design competitions and outreach maker events for middle and high school students. All activities coexist relatively harmoniously with class/event use occurring during the day and team activity concentrated in the evening hours. Opportunities for additional utilization will focus on class/event use as these activities are typically low cost and occur during the day when center utilization is lower.

\section{Analysis of Training Completions}

Table 2 and Figures 2 and 3 summarize training classes and completions for the center from inception to the current year. In the early years of the center, an annual environmental, health, and safety (EHS) class was required for all students. Many students on competition teams arrived with fabrication skills and training for other students could be provided on an as-needed basis by these skilled students or staff members.

\begin{tabular}{|l|c|c|c|c|c|c|c|}
\hline Training Classes & $2011-12$ & $2012-13$ & $2013-14$ & $2014-15$ & $2015-16$ & $2016-17$ & $2017-18^{*}$ \\
\hline Total Class Offerings & 0 & 2 & 2 & 5 & 99 & 135 & 72 \\
\hline Total Student Enrollments & & 80 & 100 & 325 & 1065 & 1309 & 1748 \\
\hline Required for Entry & & 80 & 100 & 150 & 582 & 641 & 1374 \\
\hline Required for Shops & & & & 175 & 375 & 405 & 257 \\
\hline Optional Enrollments & & & & & 108 & 263 & 117 \\
\hline
\end{tabular}

Table 2 - Summary of BIC Training Class History (2017-18 is partial year)

With the addition of capstone design projects and increasing student numbers in general, the need for more formal and comprehensive training in safety or skill became critical. Table 3 summarizes the classes offered to center students. All classes are offered in the late afternoon and evening time, usually last for two hours, and they are not for academic credit. The training necessary to enter the center is being offered as online modules to support the increasing number of students using the center. The data in Table 3 depict the typical four classes per week that were offered in 2016-17 with an average class size of 9.7. The shop classes are capped at six students. 


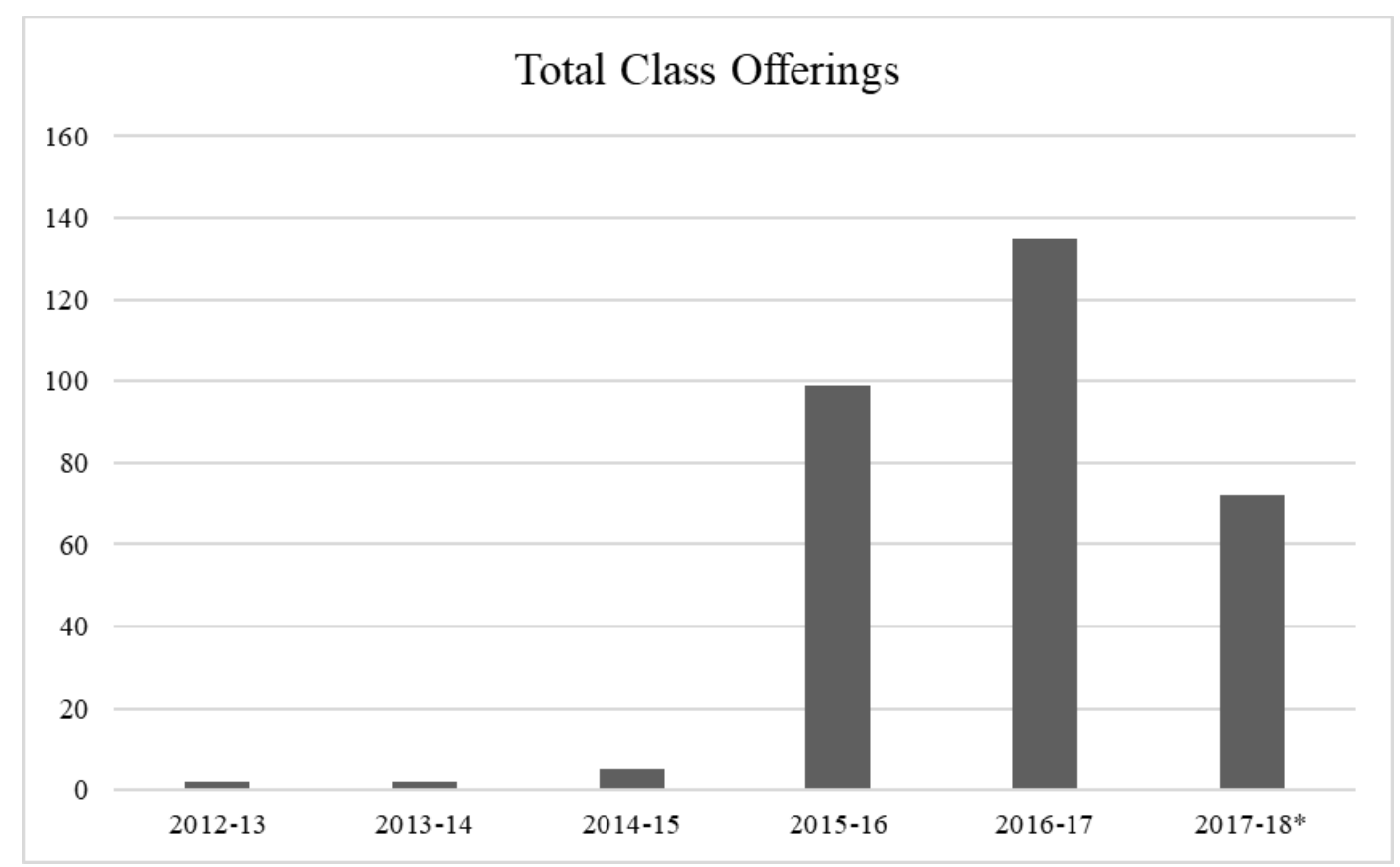

Figure 2 - Summary of BIC Class Offerings (2017-18 is partial year)

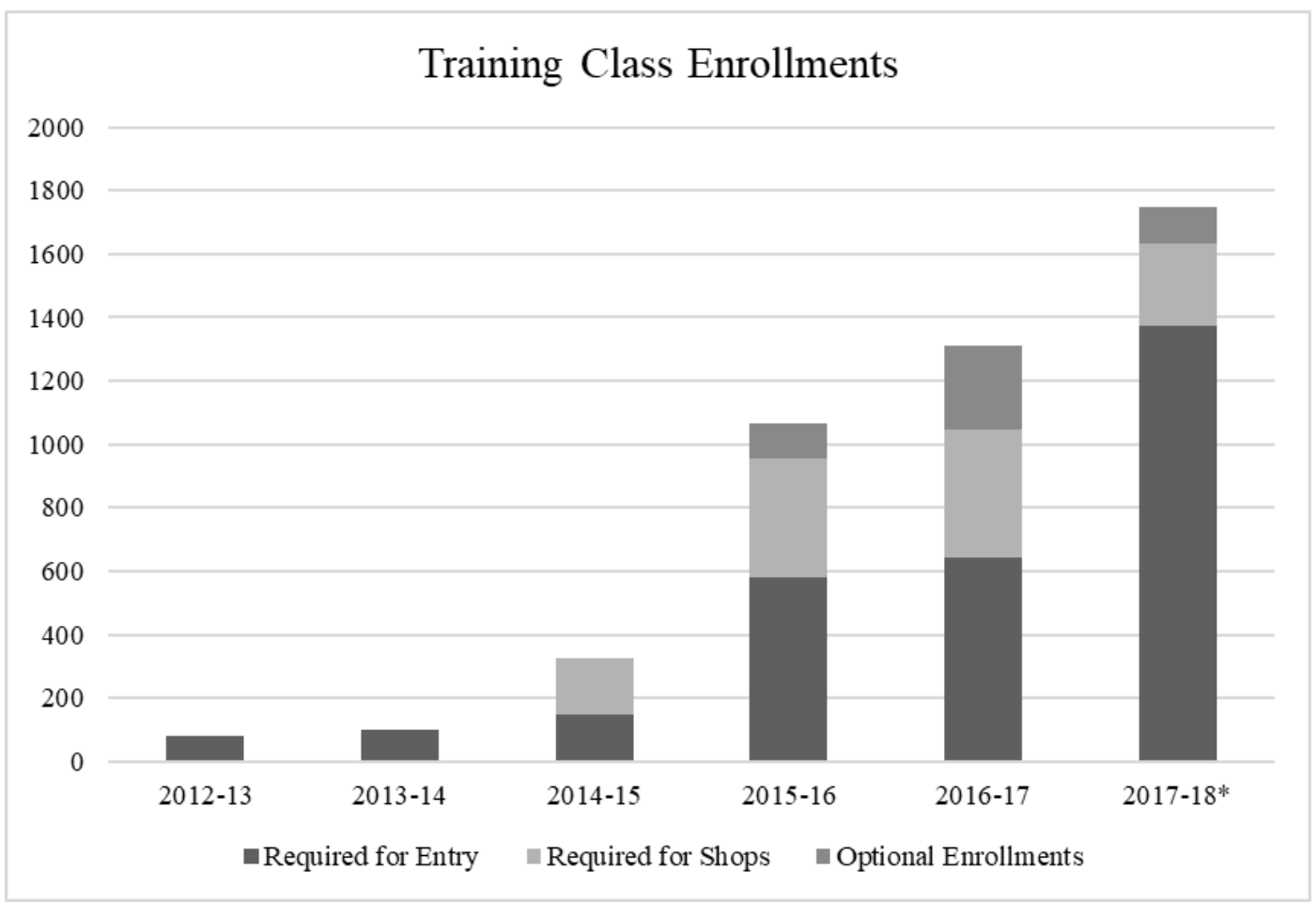

Figure 3 - Summary of BIC Training Class Enrollments

(a. 2017-18 is partial year and b. many students enroll in multiple classes) 


\begin{tabular}{|l|c|c|c|c|c|c|}
\hline Training Class & $\begin{array}{c}\text { Duration } \\
\text { (Hour) }\end{array}$ & F2F & Online & $\begin{array}{c}\text { Entry to } \\
\text { Center }\end{array}$ & $\begin{array}{c}\text { Entry to } \\
\text { Shops }\end{array}$ & Optional \\
\hline Intro to EHS & 1 & & $\mathrm{X}$ & $\mathrm{X}$ & & \\
\hline Intro to 5S & 1 & & $\mathrm{X}$ & $\mathrm{X}$ & & \\
\hline Shop Safety & 1 & $\mathrm{X}$ & & & $\mathrm{X}$ & \\
\hline Shop Safety Refresh & 1 & $\mathrm{X}$ & & & $\mathrm{X}$ & \\
\hline Intro to Shop Practices & 2 & $\mathrm{X}$ & & & & $\mathrm{X}$ \\
\hline Shop Practices - Lathe & 2 & $\mathrm{X}$ & & & & $\mathrm{X}$ \\
\hline Shop Practices - Mill & 2 & $\mathrm{X}$ & & & & \\
\hline Shop Practices- Bench & 2 & $\mathrm{X}$ & & & $\mathrm{X}$ & \\
\hline Intro to Welding & 2 & $\mathrm{X}$ & & & $\mathrm{X}$ & \\
\hline Intro to Welding Refresh & 1 & $\mathrm{X}$ & & & & $\mathrm{X}$ \\
\hline Welding 1 & 2 & $\mathrm{X}$ & & & & $\mathrm{X}$ \\
\hline Welding 2 & 2 & $\mathrm{X}$ & & & & $\mathrm{X}$ \\
\hline Welding 3 & 2 & $\mathrm{X}$ & & & & $\mathrm{X}$ \\
\hline TIG & 2 & $\mathrm{X}$ & & & & $\mathrm{X}$ \\
\hline Precision Measurements & 2 & $\mathrm{X}$ & & & & $\mathrm{X}$ \\
\hline Maker - Copper Jewelry & 2 & $\mathrm{X}$ & & & & \\
\hline Maker - Birdhouse & 2 & $\mathrm{X}$ & & & & \\
\hline
\end{tabular}

Table 3 - Summary of Training Classes Offered at the BIC

\section{Analysis of Center Utilization}

Examination of the access/lock log data provides insight into the utilization of the BIC throughout the years. With the center being locked 24/7, students present their campus ID cards at the electronic lock at the front door to gain entry. The card-entry system has captured student entry records into the center since the winter quarter of 2014-15. Our analysis includes only student entry records. Faculty/staff entries, duplicate student attempts, and middle/high school visitor entries were removed prior to aggregating access records by academic year, quarter, week, day, and hour. Our campus is on a three-quarter system rather than two semesters. We believe that the lock data are a conservative estimate of the number of student entries due to the situation where one student may scan their ID while additional students may enter on this one log entry.

As discussed earlier, the overall level of student activity, thus the utilization of the center, has increased over the last three years. For instance, the access log data summarized in Table 4 reveals there were over 21,000 student entries in the 2016-17 academic year with a $37 \%$ increase in access between academic years 2015-16 and 2016-17. In addition, the winter quarters of both years have the most frequent access by students.

\begin{tabular}{|l|r|r|r|r|r|r|}
\hline Quarter & \multicolumn{2}{|c|}{ AY 1415 } & \multicolumn{2}{|c|}{ AY 1516 } & \multicolumn{2}{|c|}{ AY 1617 } \\
\hline Fall & NA & & 3985 & $25 \%$ & 6437 & $29 \%$ \\
\hline Winter & 3763 & $45 \%$ & 6192 & $39 \%$ & 7875 & $36 \%$ \\
\hline Spring & 3925 & $47 \%$ & 5150 & $32 \%$ & 6798 & $31 \%$ \\
\hline Summer & 714 & $8 \%$ & 601 & $4 \%$ & 771 & $4 \%$ \\
\hline Total & 8402 & & 15928 & & 21881 & \\
\hline
\end{tabular}

Table 4 - Student entries to the BIC by Quarter (data for a partial year in 2014-15) 
The following analyses include data for fall, winter, spring, and summer periods. Even though activity is much lower in the summer, the data are included to maintain consistency. It is also noted that the 2014-15 year represents a partial year data for winter through the summer periods. Analyzing by the ten weeks of academic instruction in an academic quarter, Table 5 shows that during 2015-16 and 2016-17 the center has a relatively even number of visits in weeks 1 to 10 with the most visits by students during Week 8 of the 12 -week quarterly schedule. The number of visits drops during week 11, which is finals week, and during quarter break.

\begin{tabular}{|l|r|r|r|r|r|r|}
\hline $\begin{array}{l}\text { Week of } \\
\text { Quarter }\end{array}$ & AY 14-15 & \multicolumn{2}{|c|}{ AY 15-16 } & \multicolumn{2}{|c|}{ AY 16-17 } \\
\hline Week 1 & 370 & $4 \%$ & 1491 & $9 \%$ & 1875 & $9 \%$ \\
\hline Week 2 & 811 & $10 \%$ & 1369 & $9 \%$ & 1964 & $9 \%$ \\
\hline Week 3 & 883 & $11 \%$ & 943 & $6 \%$ & 2020 & $9 \%$ \\
\hline Week 4 & 741 & $9 \%$ & 1474 & $9 \%$ & 1697 & $8 \%$ \\
\hline Week 5 & 810 & $10 \%$ & 1293 & $8 \%$ & 1753 & $8 \%$ \\
\hline Week 6 & 827 & $10 \%$ & 1487 & $9 \%$ & 2055 & $9 \%$ \\
\hline Week 7 & 812 & $10 \%$ & 1409 & $9 \%$ & 2101 & $10 \%$ \\
\hline Week 8 & 777 & $9 \%$ & 1657 & $10 \%$ & 2353 & $11 \%$ \\
\hline Week 9 & 740 & $9 \%$ & 1478 & $9 \%$ & 2256 & $10 \%$ \\
\hline Week 10 & 803 & $10 \%$ & 1494 & $9 \%$ & 2181 & $10 \%$ \\
\hline Week 11 & 425 & $5 \%$ & 733 & $5 \%$ & 620 & $3 \%$ \\
\hline Break & 403 & $5 \%$ & 1100 & $7 \%$ & 1006 & $5 \%$ \\
\hline Total & 8402 & & 15928 & & 21881 & \\
\hline
\end{tabular}

Table 5 - Student entries to the BIC by Week of Quarter

Analyzing by day of week, Table 6 shows that for the three years studied, Wednesdays consistently have the most number of visits from students followed by Tuesdays and Thursdays. These results reflect that some capstone design classes meet and work at the center on Wednesdays. Tuesdays and Thursdays are often workdays for competition teams. These results also show the importance of weekend hours with $20 \%$ of visits occurring on Saturdays and Sundays.

\begin{tabular}{|l|r|r|r|r|r|r|}
\hline Day of Week & AY 2014-15 & \multicolumn{2}{|c|}{ AY 2015-16 } & \multicolumn{2}{|c|}{ AY 2016-17 } \\
\hline Mon & 1166 & $14 \%$ & 2021 & $13 \%$ & 2984 & $14 \%$ \\
\hline Tue & 1445 & $17 \%$ & 2944 & $18 \%$ & 3583 & $16 \%$ \\
\hline Wed & 1752 & $21 \%$ & 3434 & $22 \%$ & 5286 & $24 \%$ \\
\hline Thu & 1332 & $16 \%$ & 2638 & $17 \%$ & 3187 & $15 \%$ \\
\hline Fri & 1017 & $12 \%$ & 1964 & $12 \%$ & 2476 & $11 \%$ \\
\hline Sat & 1014 & $12 \%$ & 1572 & $10 \%$ & 2302 & $11 \%$ \\
\hline Sun & 676 & $8 \%$ & 1355 & $9 \%$ & 2063 & $9 \%$ \\
\hline Total & 8402 & $100 \%$ & 15928 & $100 \%$ & 21881 & $100 \%$ \\
\hline
\end{tabular}

Table 6 - Student entries to the BIC by Day of Week 
Analyzing by class hour of the day, Table 7 shows entries to the center increase during the day with the busiest time of the day being the 10th hour for academic years 2014-15 and 2015-16; however, it was during the 6th hour for academic year 2016-17. The center opens at 10 a.m. for supervised hours so entries during $1^{\text {st }}$ and $2^{\text {nd }}$ hours represent students with $24 / 7$ independent access to the center.

\begin{tabular}{|l|l|r|r|r|r|r|r|}
\hline \multicolumn{2}{|l|}{ Time of Day } & \multicolumn{2}{|c|}{ AY 2014-15 } & \multicolumn{2}{|c|}{ AY 2015-16 } & \multicolumn{2}{|c|}{ AY 2016-17 } \\
\hline AM & Midnight to 8:05 am & 222 & $3 \%$ & 479 & $3 \%$ & 909 & $4 \%$ \\
\hline 1st & $8: 05$ to $8: 55$ & 201 & $2 \%$ & 241 & $2 \%$ & 497 & $2 \%$ \\
\hline 2nd & $9: 00$ to $9: 50$ & 220 & $3 \%$ & 483 & $3 \%$ & 611 & $3 \%$ \\
\hline 3rd & $9: 55$ to $10: 45$ & 461 & $5 \%$ & 912 & $6 \%$ & 1074 & $5 \%$ \\
\hline 4 th & $10: 50$ to $11: 40$ & 444 & $5 \%$ & 874 & $5 \%$ & 1000 & $5 \%$ \\
\hline 5th & $11: 45$ to $12: 35$ & 669 & $8 \%$ & 1214 & $8 \%$ & 1590 & $7 \%$ \\
\hline 6th & $12: 40$ to $1: 30$ & 715 & $9 \%$ & 1336 & $8 \%$ & 1970 & $9 \%$ \\
\hline 7 th & $1: 35$ to $2: 25$ & 516 & $6 \%$ & 1205 & $8 \%$ & 1525 & $7 \%$ \\
\hline 8 th & $2: 30$ to $3: 20$ & 658 & $8 \%$ & 1008 & $6 \%$ & 1435 & $7 \%$ \\
\hline 9th & $3: 25$ to $4: 15$ & 802 & $10 \%$ & 1182 & $7 \%$ & 1672 & $8 \%$ \\
\hline 10 th & $4: 20$ to 5:10 & 858 & $10 \%$ & 1454 & $9 \%$ & 1633 & $7 \%$ \\
\hline PM & $5: 10$ pm to Midnight & 2636 & $31 \%$ & 5540 & $35 \%$ & 7965 & $36 \%$ \\
\hline Total & & 8402 & & 15928 & & 21881 & \\
\hline
\end{tabular}

Table 7 - Student entries to the BIC by Time of Day

By partitioning a typical day into morning hours (12:00 - 8:04 a.m.), class hours (8:05 a.m. 5:10 p.m.), and evening hours (5:11 - 11:59 p.m.), Table 8 shows the busiest time for the center for the past three years was consistently during class hours followed by evening hours, then by morning hours. Over half of the annual student visits to the center were during the class hours. However, these results also show the importance of evening hours with $40 \%$ of visits occurring outside of the 8 a.m. to 5 p.m. day.

\begin{tabular}{|l|l|r|r|r|r|r|r|}
\hline Time of Day & \multicolumn{2}{|c|}{ AY 2014-15 } & AY 2015-16 & \multicolumn{2}{|c|}{ AY 2016-17 } \\
\hline AM & Midnight to 8:04 am & 479 & $3 \%$ & 888 & $4 \%$ & 909 & $4 \%$ \\
\hline CH & $8: 05$ to $5: 10$ & 9909 & $62 \%$ & 12490 & $59 \%$ & 13007 & $59 \%$ \\
\hline PM & $5: 11$ to $11: 59 \mathrm{pm}$ & 5540 & $35 \%$ & 7732 & $37 \%$ & 7965 & $36 \%$ \\
\hline Total & & 15928 & & 21110 & & 21881 & \\
\hline
\end{tabular}

Table 8 - Student entries to the BIC by AM, Class Hours, and PM

Analyzing the data by the unique student visits to the center, Table 9 shows that there were 725 different students visiting the center in 2016-17. The gender profile for these students is also shown in Table 9 with the percentages of female students aligning with overall campus figures of $22 \%$ and $25 \%$ for the full-year in 2015-16 and 2016-17 respectively.

\begin{tabular}{|l|r|r|r|r|r|r|}
\hline Gender & \multicolumn{2}{|c|}{ AY 2014-15 } & \multicolumn{2}{|c|}{ AY 2015-16 } & \multicolumn{2}{|c|}{ AY 2016-17 } \\
\hline Female & 80 & $21 \%$ & 115 & $20 \%$ & 189 & $26 \%$ \\
\hline Male & 294 & $79 \%$ & 471 & $80 \%$ & 536 & $74 \%$ \\
\hline Total & 374 & & 586 & & 725 & \\
\hline
\end{tabular}

Table 9 - Student visitors to the BIC by Gender 
With the majority of students visiting the center are undergraduate STEM students, analyzing the racial and ethnic profile of the undergraduate student visitors in 2016-17 as shown in Table 10 reveals a similar pattern to the general undergraduate student population in the STEM fields.

\begin{tabular}{|l|r|r|}
\hline Racial/Ethnic Group & $\begin{array}{r}\text { UG Visitors } \\
\text { (AY 2016-17) }\end{array}$ & $\begin{array}{r}\text { UG CS/ENG } \\
\text { (Fall 2016) }\end{array}$ \\
\hline American Indian or Alaska Native & $0.3 \%$ & $0.1 \%$ \\
\hline Asian & $5.8 \%$ & $4.6 \%$ \\
\hline Black or African American & $2.1 \%$ & $2.4 \%$ \\
\hline Hispanics of any race & $4.4 \%$ & $4.3 \%$ \\
\hline Native Hawaiian or Other Pacific Islander & $0.3 \%$ & $0.1 \%$ \\
\hline Nonresident Alien & $11.2 \%$ & $12.5 \%$ \\
\hline Two or more races & $3.6 \%$ & $3.9 \%$ \\
\hline Unknown & $0.6 \%$ & $0.2 \%$ \\
\hline White & $71.7 \%$ & $71.9 \%$ \\
\hline Total & 704 & 2054 \\
\hline
\end{tabular}

Table 10 - UG visitors to the BIC and UG STEM Enrollment by Race/Ethnicity in 2016-17

Analyzing the unique student visits by class standing, Table 11 shows a shift from heavy senior participation in 2014-15 to a more balanced representation in 2016-17. Reasons for this shift are not clear, but this may be the result of marketing the center programs to prospective students during their visits to campus.

\begin{tabular}{|l|r|r|r|r|r|r|}
\hline Class Standing & AY 2014-15 & \multicolumn{2}{|c|}{ AY 2015-16 } & \multicolumn{2}{|c|}{ AY 2016-17 } \\
\hline FR & 5 & $1 \%$ & 9 & $2 \%$ & 27 & $4 \%$ \\
\hline SO & 14 & $4 \%$ & 25 & $4 \%$ & 172 & $24 \%$ \\
\hline JR & 25 & $7 \%$ & 133 & $23 \%$ & 151 & $21 \%$ \\
\hline SR & 301 & $80 \%$ & 393 & $67 \%$ & 354 & $49 \%$ \\
\hline GRAD & 29 & $8 \%$ & 26 & $4 \%$ & 21 & $3 \%$ \\
\hline Total & 374 & & 586 & & 725 & \\
\hline
\end{tabular}

Table 11 - Student visitors to the BIC by Class Standing

Analyzing the unique student visits by the number of time a student visited the center in the 2016-17 year, Table 12 shows that over half of students entered the center less than 10 times and only $7 \%$ visited more than 100 times. Over four quarters, 100 visits correspond to two visits per week for all four quarters.

\begin{tabular}{|l|r|r|}
\hline $\begin{array}{l}\text { Visits to Center } \\
\text { per Student }\end{array}$ & AY 2016-17 \\
\hline 1 to 10 & 401 & $55 \%$ \\
\hline 11 to 100 & 272 & $38 \%$ \\
\hline$>101$ & 52 & $7 \%$ \\
\hline & 725 & \\
\hline
\end{tabular}

Table 12 - Number of visits to the BIC per student in 2016-17 


\section{Analysis of Student Assessment Data}

Student assessment studies have been administered each spring to students who have worked in the BIC during the year. These were initially satisfaction and suggestion surveys but have evolved into more comprehensive studies exploring student roles played, ABET related outcomes, and impacts on class and career readiness.

In the spring of 2017 (from May 2 to May 14, 2017), a confidential online survey was administered to students involved in an activity at the BIC. In total, 52 students provided responses to the survey. The majority of these students were involved with a competition team/club $(73 \%, \mathrm{~N}=38)$. About a quarter of students either used the BIC for their capstone projects $(15 \%, \mathrm{~N}=8)$ or were involved in other activities $(12 \%, \mathrm{~N}=6)$. The results from this survey are reported with appropriate IRB approvals.

Students were asked to indicate how much their BIC experience(s) contributed to their ability to engage in various behaviors. The response options ranged from Not at All (1) to Very Much (5). Figure 4 below highlights the percentage of respondents who indicated either Quite a Bit (4) or Very Much (5). Affirmation of establishing safety as a top priority for the center is noted with 'awareness of safety protocols' at the top of the list. Other top ranked items include manage projects, solve engineering problems, and work on multidisciplinary teams.

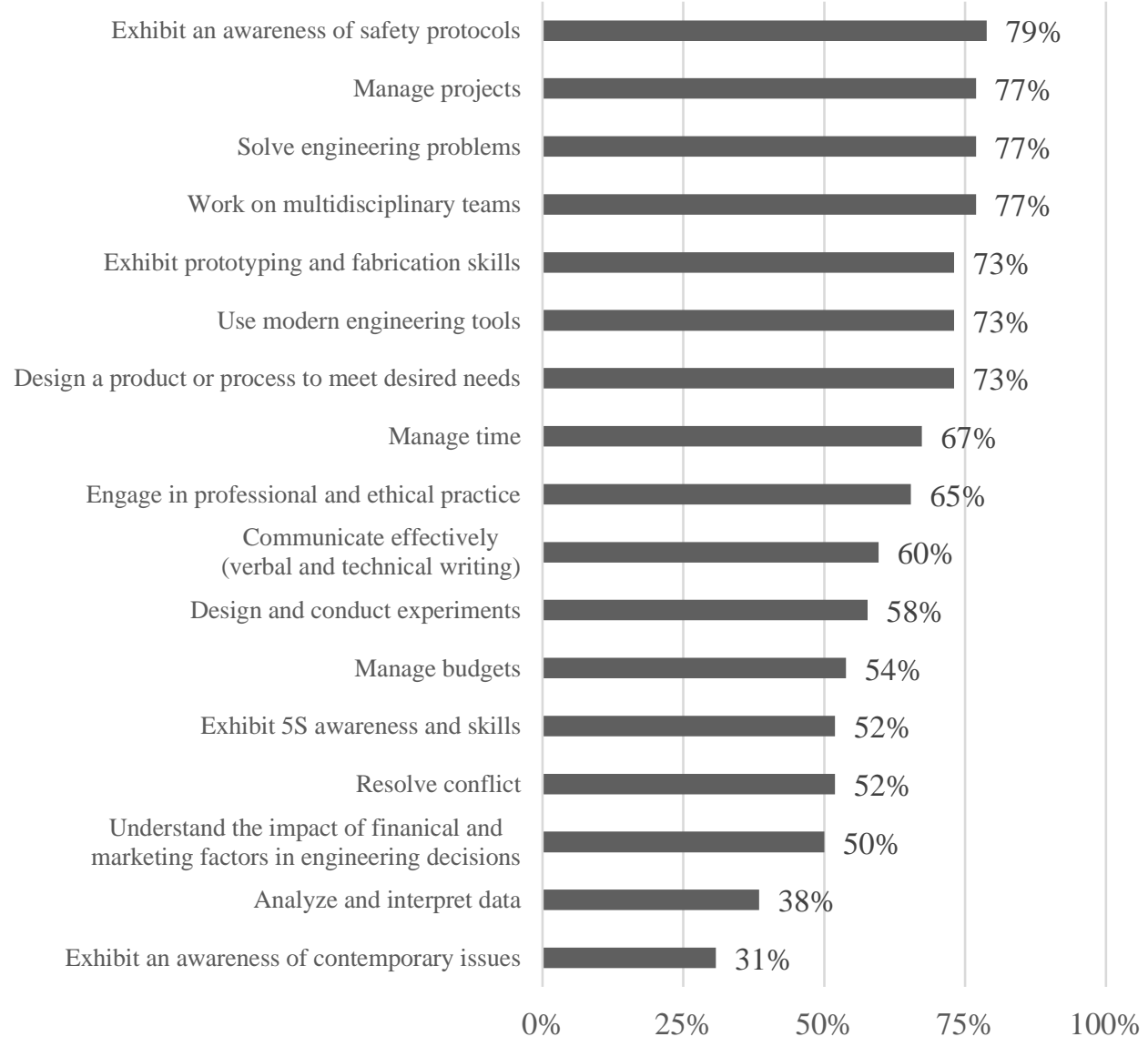

Figure 4 - Student Ability to Engage in Behaviors 
Using the same set of items, students were also asked to indicate the skills they gained at the BIC that they felt would be the most useful in the upcoming year. Over half of students indicated the following skills they gained will be the most useful: (a) design a product or process to meet desired needs (52\%, N=27); (b) work on multidisciplinary teams (52\%, N=27); and (c) solve engineering problems $(69 \%, \mathrm{~N}=36)$. More information can be seen in Table 5 below. One of the lower rated skills is exhibit $5 \mathrm{~S}$ awareness and skills. Training in 5S was offered through an optional online training module and only a few students completed it. In the current year, completing the $5 \mathrm{~S}$ module is a requirement for all students working in the center and an increase in awareness in this skill could be reflected in this year's survey.

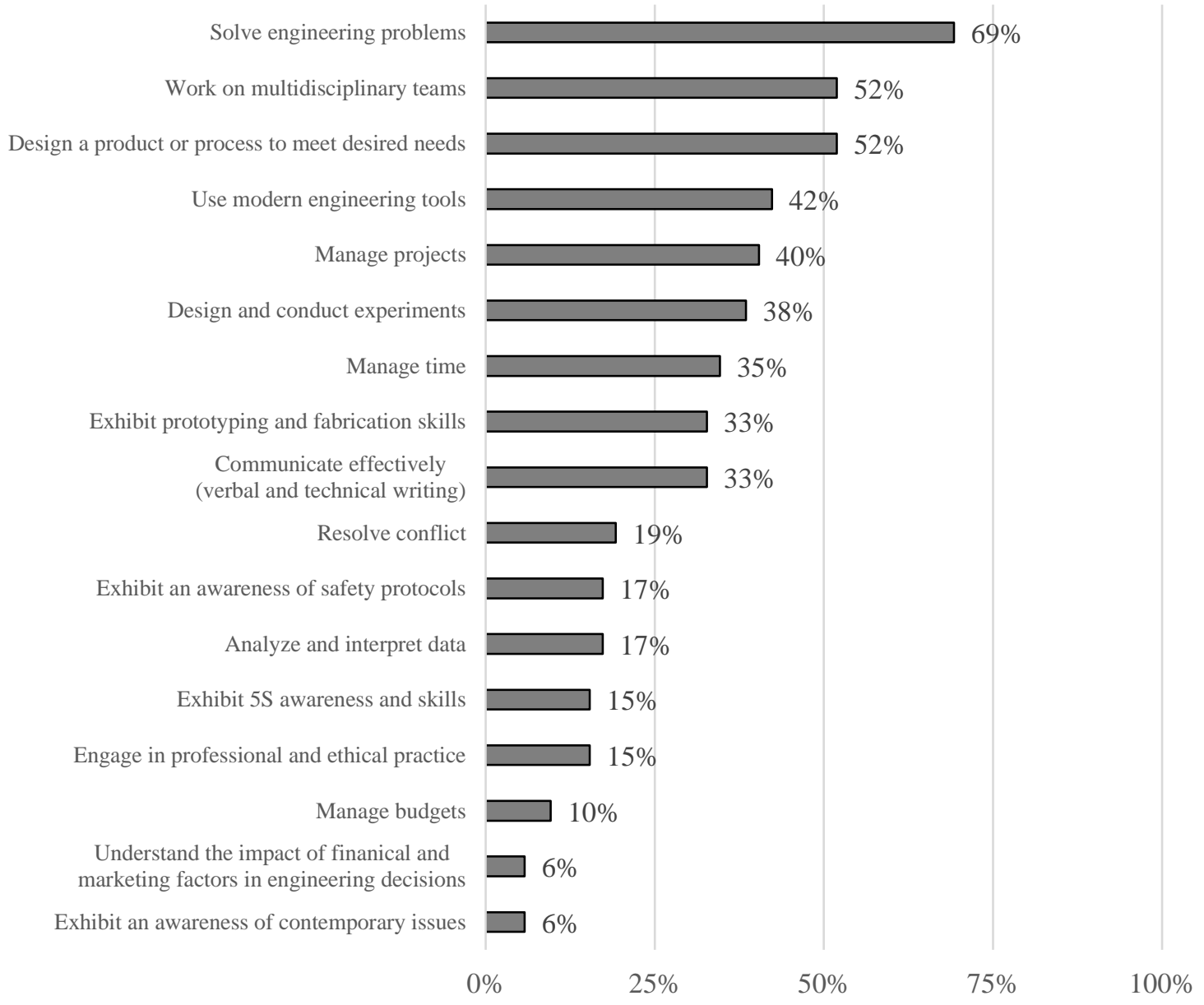

Figure 5 - Student Skills Gained Most Useful in Upcoming Year

Students were asked to indicate how often they fulfilled various roles during their BIC experience(s). These roles have been identified by Davis, et al. as defining the 'profile of an engineer performing well in professional practice ${ }^{12}$.' Further, 'the profile presents technical, interpersonal, and professional skills or behaviors that align with key roles performed by the engineer.' The response options ranged from Never (1) to Very Often (5). Table 13 below highlights the means, standard deviations, and percentage of respondents who indicated either Often (4) or Very Often (5). 
The role student fulfilled least often was Communicator $(56 \%, \mathrm{M}=3.58, \mathrm{SD}=1.11)$ and the role fulfilled most often was Self-Grower (79\%, M=4.12, SD=0.94). Self-Growers proactively learn and use resources. This favorable finding aligns with one of the new ABET learning outcomes with students possessing 'an ability to acquire and apply new knowledge as needed, using appropriate learning strategies.'

\begin{tabular}{|l|c|c|c|c|}
\cline { 2 - 5 } \multicolumn{1}{c|}{} & $M$ & $S D$ & $\begin{array}{c}\text { N(Often/Very } \\
\text { Often })\end{array}$ & $\begin{array}{c}\% \\
\text { (Often/Very } \\
\text { Often })\end{array}$ \\
\hline $\begin{array}{l}\text { Leader (take initiative in guiding the } \\
\text { project) }\end{array}$ & 3.83 & 1.18 & 34 & $65 \%$ \\
$\begin{array}{l}\text { Designer (produce work products on } \\
\text { time and within budget) }\end{array}$ & 3.83 & 1.00 & 39 & $75 \%$ \\
$\begin{array}{l}\text { Collaborator (contribute } \\
\text { constructively to team performance) }\end{array}$ & 3.88 & 0.96 & 36 & $69 \%$ \\
$\begin{array}{l}\text { Communicator (communicate } \\
\text { effectively with key stakeholders) }\end{array}$ & 3.58 & 1.11 & 29 & $56 \%$ \\
$\begin{array}{l}\text { Self-Grower (proactively learning and } \\
\text { using resources) }\end{array}$ & 4.12 & 0.94 & 41 & $79 \%$ \\
\hline
\end{tabular}

Table 13 - How Often Engineer Professional Practice Roles Fulfilled

Finally, students were asked to indicate the extent to which they agreed/disagreed with different statements about the BIC. The response options ranged from Strongly Disagree (1) to Strongly Agree (5) with results summarized in Table 14.

\begin{tabular}{|l|c|c|c|c|}
\cline { 2 - 4 } \multicolumn{1}{c|}{} & $M$ & $S D$ & $\begin{array}{c}\text { N(Agree/ } \\
\text { Strongly } \\
\text { Agree) }\end{array}$ & $\begin{array}{c}\% \text { (Agree/ } \\
\text { Strongly } \\
\text { Agree }\end{array}$ \\
\hline $\begin{array}{l}\text { I performed better in my classes because } \\
\text { of my involvement at the BIC }\end{array}$ & 3.58 & 1.09 & 25 & $48 \%$ \\
\hline $\begin{array}{l}\text { Because of my BIC experience(s), I was } \\
\text { better informed on career options }\end{array}$ & 3.85 & 1.19 & 35 & $67 \%$ \\
\hline $\begin{array}{l}\text { Because of my BIC experience(s), I was } \\
\text { better informed on what classes to take }\end{array}$ & 3.35 & 1.19 & 22 & $42 \%$ \\
\hline $\begin{array}{l}\text { Overall, I am satisfied with my BIC } \\
\text { experience(s) }\end{array}$ & 4.46 & 0.67 & 49 & $94 \%$ \\
\hline
\end{tabular}

Table 14 - Student Satisfaction and Being Informed on Class and Career Options

Findings suggest students were satisfied with their BIC experience(s) with 94\% (N=49) either agreeing or strongly agreeing to the statement, "Overall, I am satisfied with my BIC experience(s)." However, findings suggest a need to better connect the BIC experience with students' classroom experiences. Less than half of respondents agreed or strongly agreed that because of their BIC experience(s), they were better informed on what classes to take (42\%, $\mathrm{M}=3.35, \mathrm{SD}=1.19)$ and performed better in their classes (48\%, $\mathrm{M}=3.58, \mathrm{SD}=1.09)$. 
Lessons Learned

The following lessons learned are offered as a result of six years of operation of the BIC.

1. Build the right culture - the center has established a collaborative, professional, and safetyaware culture. With few walls and locks, we rely on the good judgment of students to make appropriate use of equipment and resources.

2. Student experiences are a key measure of success - high quality experiences are a result of engaging culture and the right mix of facility, equipment, programming, and technical support resources.

3. Things change, build few walls - while the center has walls to restrict access to shops with hazardous equipment, the majority of the project workspace is open and reconfigurable. As activities in the center have grown, work areas are regularly reconfigured.

4. Train early and often - a comprehensive training program focused on safety, shop skills, and professional skills is essential for preparing students to work effectively in the center. Training records are kept from year to year and the records show certain students completing all of the available classes during their time on campus.

5. Space is the most precious and contentious resource - of the resources of time, money, and space, space has been the most contentious. This is perhaps comes from the perception that there is never enough and that once assigned, space assignments may be perceived to be more permanent. It has been noted that the $5 \mathrm{~S}$ training increases the ability of teams and students to use space more effectively.

6. Storage space is wasted space - in the original configuration of the center space, a large area for storage was created. Over the years, we have noted that much of what students, teams, and even staff think we need to store should be recycled or discarded. We have worked to cut in half the storage space in the center itself and have secured additional storage space on campus.

\section{Conclusions}

This paper has reported on multiple measures of activity and utilization for the Branam Innovation Center including lock logs, team rosters, training completions, and assessment results. This paper has analyzed these sources of data and has highlighted the overall growth and utilization of the center. In addition, more detailed analysis illustrates: (a) overall level of student activity over the last three years; (b) student activity broken down by time of year, quarter, and day; (c) student gender and class standing; and (d) student participation in training classes. The center has increased participation by freshman and sophomore students and has found that PM and weekend hours are desired and utilized by students.

Assessment results indicate that students are satisfied with their overall experience at the center and report that the experience contributed to their ability to engage in various behaviors with the 
top ranked items being awareness of safety protocols, manage projects, solve engineering problems, and work on multidisciplinary teams.

It is believed that these results are useful in a variety of situations including prioritizing center activities, determining operating policies, allocating space, scheduling of staff, marketing the program to students, and determining overall resource needs.

\section{$\underline{\text { References }}$}

1. Vigeant, M. A., \& Siegel, N. P., \& Marosi, K. T., \& Cheville, R. A., \& Kennedy, E. A., \& Kim, C., \& Tranquillo, J., \& Cipoletti, D. E., \& Montgomery, K., \& Mercon, K., \& Poss, L. K., \& Ross, Z. P., \& Muccio, D. R. (2015, June), Maker: \#BucknellMakers, Paper presented at 2015 ASEE Annual Conference \& Exposition, Seattle, Washington. 10.18260/p.24442

2. Forest, Craig R.; Moore, Roxanne A.; Jariwala, Amit S.; Fasse, Barbara Burks; Linsey, Julie; Newstetter, Wendy; Ngo, Peter; Quintero, Christopher (2014), The Invention Studio: A University Maker Space and Culture, Advances in Engineering Education, v4 n2 Sum 2014

3. Levy, B., \& Morocz, R. J., \& Forest, C., \& Nagel, R. L., \& Newstetter, W. C., \& Talley, K. G., \& Smith, S. F., \& Linsey, J. S. (2016, June), MAKER: How to Make a University Maker Space, Paper presented at 2016 ASEE Annual Conference \& Exposition, New Orleans, Louisiana. 10.18260/p.25623

4. Darwin, J., \& Kale, J. P., \& Thompson, M. S., \& Vigeant, M. A., \& Cheville, A. (2016, June), MAKER: A Maker Space Smart Badging System, Paper presented at 2016 ASEE Annual Conference \& Exposition, New Orleans, Louisiana. 10.18260/p.25600

5. Pung, C. P., \& Morrow, D. (2015, June), MAKER: A Practical Approach to Student Use of University Owned Rapid Prototype Machines, Paper presented at 2015 ASEE Annual Conference \& Exposition, Seattle, Washington. 10.18260/p.24446

6. Wilczynski, V. (2017, June), A Classification System for Higher Education Makerspaces, Paper presented at 2017 ASEE Annual Conference \& Exposition, Columbus, Ohio. https://peer.asee.org/27448

7. Forest, C., \& Hashemi Farzaneh, H., \& Weinmann, J., \& Lindemann, U. (2016, June), Quantitative Survey and Analysis of Five Maker Spaces at Large, Research-Oriented Universities, Paper presented at 2016 ASEE Annual Conference \& Exposition, New Orleans, Louisiana. 10.18260/p.26023

8. Barrett, T. W., \& Pizzico, M. C., \& Levy, B., \& Nagel, R. L., \& Linsey, J. S., \& Talley, K. G., \& Forest, C. R., $\&$ Newstetter, W. C. (2015, June), A Review of University Maker Spaces, Paper presented at 2015 ASEE Annual Conference \& Exposition, Seattle, Washington. 10.18260/p.23442

9. Wilczynski, V. (2015, June), Academic Maker Spaces and Engineering Design, Paper presented at 2015 ASEE Annual Conference \& Exposition, Seattle, Washington. 10.18260/p.23477

10. Morocz, R. J., \& Levy, B. D., \& Forest, C. R., \& Nagel, R. L., \& Newstetter, W. C., \& Talley, K. G., \& Linsey, J. S. (2015, June), University Maker Spaces: Discovery, Optimization and Measurement of Impacts, Paper presented at 2015 ASEE Annual Conference \& Exposition, Seattle, Washington. 10.18260/p.24967

11. Penney, M. F., \& Watkins, J. D., \& Levy, B., \& Linsey, J. S., \& Nagel, R. L., \& Newstetter, W. C., \& Talley, K. G., \& Smith, S. F. (2016, June), 'Making' an Impact: An Ethnographic Approach to University Maker Spaces, Paper presented at 2016 ASEE Annual Conference \& Exposition, New Orleans, Louisiana. $10.18260 / \mathrm{p} .26226$ 
12. Davis, D., Steven W. Beyerlein, \& Isadore T. Davis (2005, June), Development and Use of an Engineer Profile, Paper presented at 2005 Annual Conference, Portland, Oregon. https://peer.asee.org/14201

13. Bill, V., \& Fayard, A. (2017, June), Building an Entrepreneurial and Innovative Culture in a University Makerspace Paper, presented at 2017 ASEE Annual Conference \& Exposition, Columbus, Ohio.

https://peer.asee.org/27985 (print)

14. Lagoudas, M. Z., \& Froyd, J. E., \& Wilson, J. L., \& Hamilton, P. S., \& Boehm, R., \& Enjeti, P. N. (2016, June), Assessing Impact of Maker Space on Student Learning, Paper presented at 2016 ASEE Annual Conference \& Exposition, New Orleans, Louisiana. 10.18260/p.26298 